\title{
1 Introduction: Cultivating Curiosity about the Teaching of Classical Jewish Texts
}

\author{
Jon A. Levisohn and Susan P. Fendrick
}

Ben Bag Bag said: Turn it and turn it again, for all is contained within it.

Pirkei Avot (Ethics of the Fathers), 5:22

In some contexts, the teaching of Ben Bag Bag in Pirkei Avot may have already become a cliché. Of course he would say this! What else would we expect from a participant in the rabbinic project, a project that makes sense only if we assume that the Torah contains endless depths of wisdom? But a closer reading reveals that the aphorism is not only about Torah, but also about how one ought to relate to Torah. That is, Ben Bag Bag's teaching is actively promoting an inquiring attitude toward the classical texts of the Jewish tradition, towards Torah in the broader sense-what came to be known as the dual Torahs, the Oral Torah alongside the Written, the inherited teachings alongside the fixed text. Ben Bag Bag's aphorism is not merely a comment about the status of Torah, but an encouragement-even a directive-to "turn it" endlessly, to investigate it, to adopt a stance of inquiry towards text and tradition.

For those immersed in the classical texts of the Jewish traditionTanakh, midrashic collections, Mishnah and Talmud, and their commentaries-this stance is second nature. Jews ask questions about these texts. They pursue their meanings, often celebrating the questions more than the answers, and the process of inquiry more than the product. Texts are transmitted; texts are revered; but most of all, texts are studied. For outsiders to the tradition, this inquiry stance is frequently quite surprising.

In adopting Ben Bag Bag's words for the title of this book, we hope to indicate a very simple point: the teaching of classical Jewish texts deserves disciplined and focused investigation no less than do the texts themselves. We can transfer the inquiry stance that we are accustomed to take from one domain, the realm of the texts themselves, to another domain, the 
realm of teaching those texts. We can take our teaching or that of others, or the learning of students, or our conceptual models for teaching, and turn them into texts- to be studied, to generate insight and wisdom, to foster new questions, and to contribute to a culture of inquiry.

And just as the study of Torah is pursued for intellectual purposes rather than immediately practical purposes-classical Jewish texts are rarely studied to determine a halakhic ruling, except by specialists in Jewish law-so too the study of the teaching of Torah can be pursued for intellectual and scholarly purposes rather than immediately practical purposes. We can pursue a study of pedagogy lishma, for its own sake. We can discover ideas that shape how we think about teaching and learning as much as or more than they directly shape how we teach.

More than anything else, a fascination with the endlessly intriguing, endlessly surprising work of teaching is the common thread among the contributors to this volume. They refrain from promoting particular teaching techniques. They do not make claims about "best practices" based on general desirable outcomes; even where they are committed to particular approaches in specific contexts, their stance in this book is one of exploration rather than merely advocacy. In other words, to the extent that they share their approach to a particular pedagogic problem, they are exploring that approach with their readers, trying to understand it better, in the hope that what they learn in the process will be interesting to others as well. They pursue arguments, to be sure, but they refrain from "proofs." They prefer close description to categorical prescription. They analyze, and they wonder. They do not intend to tell their readers how to teach-although their work will help all of us who teach classical Jewish texts become better and more thoughtful teachers. They expose the complexity of the practice of teaching complicated texts, rather than concealing that complexity behind assertions about "what works." And so the purpose of this book, we might say, is to cultivate curiosity about the teaching and learning of classical Jewish texts, to question and wonder, to help all of us to think about this work with greater depth and creativity.

Beyond this point, the studies collected here draw on three interwoven intellectual traditions in educational research: a focus within educational research on subject-specific pedagogical knowledge, the movement in academia known as the Scholarship of Teaching and Learning (often abbreviated as "SoTL"), and the broader trend (particularly in K-12 educa- 
tion) of teacher research. All three of those traditions were influential in the design and execution of our original research project-the Initiative on Bridging Scholarship and Pedagogy in Jewish Studies—at the Mandel Center for Studies in Jewish Education at Brandeis University, which gathered together teachers and scholars in a set of seminars and conferences over a number of years, and which generated a large set of working papers on a variety of issues in the teaching of Tanakh and rabbinic literature. Versions of many of those papers appear in this volume.

The first of these three intellectual traditions emerged in the early 1980s, when Lee Shulman called attention to what he called a "missing paradigm" in educational research, ${ }^{1}$ a problem that he was pursuing and continued to pursue with colleagues and numerous students at Stanford. ${ }^{2}$ The missing paradigm to which Shulman called attention was an approach that places subject matter at the heart of pedagogic inquiry, that recognizes the complexity of subject-specific pedagogic challenges, and that takes the question of teachers' subject matter knowledge (and what they do with that knowledge) seriously. Along the way, he rejected the sharp bifurcation of teacher knowledge into general pedagogical knowledge, on the one hand, and content knowledge, on the other. It is important that teachers know their subjects, and it is important that they possess certain kinds of generic knowledge about teaching. But the most important things that they know fall into a category that he called "pedagogical content knowledge" or PCK-the knowledge of how to guide students into and through a particular content area, of how to take the fundamental concepts within that content area and represent them in multiple ways, of how to frame the overarching intellectual structures within that area, of what is particularly challenging within that area and how to work around those challenges. In terms of research, then, the most interesting questions about teaching - and the most significant questions to pursue, to serve the practical purposes of

1 Lee Shulman, "Those Who Understand: Knowledge Growth in Teaching," Educational Researcher (1986): 4-14.

2 The following draws on material previously published by one of the editors: Jon A. Levisohn, "Strengthening Research on the Pedagogy of Jewish Studies: Introduction to a Suite of Articles on Teaching Bible," Journal of Jewish Education 74:1 (2008), and Jon A. Levisohn, "Building Bridges to Overcome Breaches: School and Academy, Content and Pedagogy, Scholarship and Teaching," South Atlantic Philosophy of Education Society (SAPES) 2008 Yearbook, 2009. 
teacher education and professional development-are questions about how teachers actually approach a particular subject-specific pedagogical challenge, and how they might do so.

The second tradition to which we referred above is the Scholarship of Teaching and Learning. The term "scholarship of teaching" was first coined by Ernest Boyer in an effort to elevate the work of teaching to a more prominent status within academia. ${ }^{3}$ Since that time, thanks again to the work of Lee Shulman among others, it has developed the more specific meaning of scholarly inquiry by academics in particular disciplines into the practice of teaching those disciplines. Academics who pursue the Scholarship of Teaching and Learning expand their research agendas in order to make teaching and/or learning the focus of disciplined research and writing, knowing that specialists with a deep and rich knowledge of the subject matter can conduct research on the nuances of teaching their particular subject that outsiders to the field will be hard pressed to pursue. Like other forms of scholarship, the scholarship of teaching must become publicly accessible, and it must be subject to peer review and critique, turning teaching from private property into communal property. ${ }^{4}$ Paradigmatically, SoTL is a product of inquiry into the teaching that one knows best-namely, one's own.

The scholarship of teaching is not oriented towards the evaluation of teaching, nor does it focus on remediation, the diagnosis and correction of problems. It is not simply synonymous with reflection on teaching or "reflective practice," but is characterized by a qualitatively deeper level of inquiry facilitated by close attention to records of practice such as lesson plans, videotapes, students' work, or teacher journals. ${ }^{5}$ Scholars

3 Ernest Boyer, Scholarship Reconsidered: Priorities of the Professoriate (San Francisco: Jossey-Bass, 1990).

4 Lee Shulman, "Teaching as Community Poperty: Putting an End to Pedagogical Solitude," Change 25 (1993): 6-7.

5 Barry Holtz, "Across the Divide: What Might Jewish Educators Learn from Jewish Scholars?," Journal of Jewish Education 72 (2006): 5-28, quotes Chris Argyris and Donald Schon, Theory in Practice: Increasing Professional Effectiveness (San Francisco: Jossey-Bass, 1974), who argue that practitioners are not the best theorists of their own practice, at least not without help: "We cannot learn what someone's theory-in-use is simply by asking him. We must construct his theory-in-use from observations of his behavior" (9). This is one reason why SoTL thrives when it has access to artifacts of teaching that can serve as data for analysis, as many of the chapters in this volume do. 
pursuing SoTL do not just muse about how their teaching went that day; ideally, they ask specific, researchable questions, and gather data that can illuminate those questions. Most basically, the scholarship of teaching can pursue a deeper understanding of a particular aspect of teaching or of student learning about which a professor is simply curious, holding normative questions (about whether this is a good practice, much less the best practice) in abeyance.

While SoTL is an emerging research tradition within higher education, there is also a third research tradition known as teacher research, or (somewhat more broadly) practitioner inquiry, found primarily within K-12 education. Where SoTL tends to use the language of academic research and to be oriented toward the development of a field of scholarship (in which studies refer to each other, build on each other, and accumulate into a scholarly tradition), teacher research tends to be focused more on the contribution that an inquiry stance can make towards the professional development of the practitioner. Indeed, the phrase "inquiry as stance," coined by Marilyn Cochran Smith and Susan Lytle, ${ }^{6}$ signals this focus: the purpose of teacher research is not primarily to develop new knowledge but to cultivate a stance by teachers toward their work characterized by inquisitiveness and curiosity-about their own teaching, about student learning, and about the conditions within which they work. There is also an important political thrust here, empowering teachers as agents of change rather than as subjects of the research of others and of policies dictated to them.

Consistent with Shulman's call for attention to the "missing paradigm" of subject-specific pedagogical research (sometimes framed in terms of research on PCK), this book focuses on the teaching of specific subjects, the classical texts of the Jewish tradition. As in the Scholarship of Teaching and Learning, these studies pursue and promote the development of a relatively new research tradition, making pedagogy the focus of scholarly inquiry. And in the tradition and spirit of practitioner research, most of the chapters are written by instructors of classical Jewish texts investigating or exploring their own practice.

It is worth noting that all three of these traditions-and this bookreject the idea of a sharp and distinct division of labor between scholars

6 See most recently Marilyn Cochran-Smith and Susan L. Lytle, Inquiry as Stance: Practitioner Research for the Next Generation (New York: Teachers College Press, 2009). 
and teachers, and likewise reject a sharp conceptual distinction between scholarship and pedagogy. What does this mean? According to a fairly well-entrenched model of education, one group of people, the scholars, produce knowledge; they generate the material to be taught, the "what" of teaching. Then another group of people, the teachers, transmit the knowledge; they are experts on the "how" of teaching. (In addition to the producers and the transmitters, there is a third group of people in the model - the students - who are conceived as consumers.) The divisionof-labor model and its corollary conceptual distinction are pervasive. History teachers go to the Holocaust Museum and study history with historians, on the one hand, or they sit with their colleagues and learn about writing across the curriculum, on the other. Teachers of Tanakh go to hear lectures from masterful scholars of Bible, or they learn about multiple intelligences. Doctoral students on their way to the professoriate become expert in their specialties, and grab a few ideas along the way about leading discussions or grading exams. And most fundamentally, teacher education programs are often divided quite literally between "content" courses and "pedagogy" courses, where the former contain intellectual substance and the latter, too frequently, are "practical," in the sense of providing training in techniques rather than exploration of ideas.

But thinking this way about pedagogy is neither useful nor perceptive. It is not useful because, as Deborah Ball writes, it "tends to fragment practice and leaves to individual teachers the challenge of integrating subject matter knowledge and pedagogy in the context of their work." If the real work of teaching requires this integration, then treating the subject in a fragmented way avoids all the hard problems, and encourages idiosyncratic solutions rather than principled ones. And it is not perceptive because, just as there is no pure pedagogy without content, so too there is no pure scholarship without audience. Pedagogy is always the teaching of particular students about something, and scholarship is always the communication of ideas about a particular topic to someone, some intended audience with anticipated understandings and misunderstandings. Once the scholar formulates her ideas in some way in order to present them to others - colleagues at a conference, students in a lecture hall or a lab, or some dimly perceived readership of the par-

7 Deborah Ball, "Bridging Practices: Intertwining Content and Pedagogy in Teaching and Learning to Teach," Journal of Teacher Education, 51:3 (2000): 242. 
ticular scholarly journal to which she is submitting her article-she is already, we might say, engaged in the work of pedagogy. So the work of scholarship and the work of teaching are much more similar than they are often understood to be.

What the reader will find in this book, then, are substantive investigations of teaching, often grounded in records of practice, and always attuned to the specific questions that arise about the teaching of Tanakh and rabbinic literature in particular contexts. The authors are smart and thoughtful, and passionate about their work as instructors in the many and varied settings in which they teach. But most of all, they are curious. And this, as noted above, is the agenda of the book as a whole. Beyond particular insights into teaching classical Jewish texts, beyond conceptual frameworks and new language about this work, beyond advancing the field of research into subject-specific pedagogy and building up the traditions of the scholarship of teaching and teacher research, our aim in this volume is to foster in the reader the shared conviction that teaching is deserving of close attention, and that such close attention is rewarded with greater insight and understanding. It aims, in other words, to cultivate professional curiosity.

The book is organized in four sections with four foci: subject matter, teaching and teachers, learning and learners, and context. For many readers, this division will be familiar from Joseph Schwab's four educational commonplaces, ${ }^{8}$ or from the instructional triangle of teacher-student-content situated within a circle representing the particular context or milieu. ${ }^{9}$ But astute readers will note that the adoption of Schwab's commonplaces for this structural purpose is inevitably problematic. After all, Schwab's point is that all of these elements are at play in instruction. In any given setting, all four of them deserve consideration. Likewise, the power of the instructional triangle as a model of teaching

8 See Joseph Schwab, “The Practical 3: Translation into Curriculum," School Review 81:4 (1973): 501-522.

9 David Cohen and Deborah Loewenberg Ball, Instruction, Capacity, and Improvement (CPRE Research Report No. RR-43) (Philadelphia: University of Pennsylvania, Consortium for Policy Research in Education, 1999), and David Hawkins, "I, Thou, and It," in his The Informed Vision: Essays on Learning and Human Nature (New York: Agathon Press, 1974), 48-62. 
is that it replaces a more simplistic model of teaching as the transmission of content from teacher to student. Instead, the instructional triangle conceptualizes teaching as always involving a set of ongoing, dynamic relationships: the (evolving) relationship between the teacher and the student, the (evolving) relationship between the teacher and the content, and the (evolving) relationship between the student and the content, which the teacher is working to facilitate.

What this means, then, is that the organization of the book into these four foci is unavoidably artificial. None of these chapters is only about teaching, or only about subject matter. Every time we talk about teaching, we are inevitably also talking about students. Every time we talk about a particular subject, we are inevitably also talking about the context in which that subject is being pursued. If we have nevertheless decided to organize the book as we have done, it is because certain chapters focus relatively more on one element and less on the other commonplaces; in each chapter, we can usefully view one as the figure, and the others the ground.

Beyond this organizational scheme for the book, there are other connections and relationships between chapters and across sections that are worth highlighting. First, this volume presents a very wide range of settings in which classical Jewish texts are taught. These include day schools, universities, and rabbinical seminaries, of course, but also include summer camp (Chapter 6, Kanarek), the synagogue pulpit (Chapter 7, Perkins), kindergarten and first-grade classrooms (Chapter 13, Horowitz), and adult education programs (Chapter 14, Cousens et al.). This is intentional. It challenges the presumption that there is one paradigm-one place (the yeshiva or the university) where the subject is really pursued. Moreover, this diversity is designed to promote the idea that we can often learn more than we might have expected from diversity. It is entirely natural for readers to look, first, to those chapters that focus on teaching that looks like their own. But we encourage our readers to explore more broadly, and to be open to both unexpected similarities and instructive differences.

Second, there are interesting and important questions to be asked about the similarities and differences between the pedagogic issues in the teaching of Tanakh and the teaching of rabbinic literature. For example, in recent years some Jewish day schools have moved towards a sharper differentiation of the teaching of Tanakh and rabbinic litera- 
ture, in accordance with the professional norms of the academy, where the study of Bible (and other texts of the Ancient Near East) is distinct from the study of rabbinic texts (and other texts of the Greco-Roman, Sassanian Persian, and Arabic cultures). But other Jewish day schools have moved in the opposite direction, intentionally blurring the line between biblical and rabbinic literature, precisely in order to focus on the interpretive skills required to approach and understand classical texts in general. In this volume, most chapters focus exclusively on one or the other, and in fact, there are two pairs of chapters that highlight that specialization: Chapter 2 (Holtz) develops a set of orientations to the teaching of Tanakh, while Chapter 3 (Levisohn) develops a set of orientations to the teaching of rabbinic literature, and Chapter 10 (Tanchel) explores the teaching of Tanakh at a particular pluralistic Jewish high school while Chapter 11 (Spitzer) explores the teaching of rabbinic literature at that same high school. On the other hand, Chapter 7 (Perkins) blurs the categories in its focus on the development of derashot, sermons or study sessions in the synagogue that typically draw on both biblical and rabbinic texts, and Chapter 12 (Kent) likewise blurs the categories in its focus on the practice of havruta, paired study of classical texts, both biblical and rabbinic. Chapter 9 (Satlow) does not engage directly with the teaching of texts so much as with the teaching of the historical culture in which those texts are situated.

Third and finally, most (although not all) of the chapters in this book present studies of practice, grounded in records of practice, often records of the author's own practice. Earlier in this introduction, we discussed the traditions of inquiry on which the book draws, but it is worth emphasizing that many of the authors have set about studying their teaching, formulating research questions, gathering relevant data (everything from student work to videotapes of classrooms to teaching journals), and analyzing that data in order to arrive at conclusions that are more than just impressions, and insights that are more than just reflections. This is not familiar work; even those authors who have been trained as researchers in their respective fields have had to learn a new way of thinking about research in order to study their practice. For this they deserve our admiration. On the other hand, none of the authors expect that their work is beyond critique. Indeed, their hope, and our hope as the editors of this book, is that these studies-individually and collectively-will serve as the basis for new explorations, for inquiries 
that are well-grounded conceptually and empirically, for the kind of ongoing conversation that is the hallmark of a tradition of scholarship.

But why? What do we hope to accomplish? Earlier, we wrote that the purpose of this book, at the most abstract level, is to cultivate curiosity about the teaching and learning of classical Jewish texts. Hopefully, this introduction has helped to make it clear how the teaching and learning of classical Jewish texts is the kind of thing that one might be curious about. What remains to be said is why that curiosity is important.

The study of Jewish texts, we believe, remains hidebound and parochial. Not everywhere, of course; there are many wonderful examples of talented and inspirational teaching at every level and setting. But as a field, for the most part, we do things because (we believe that) this is how they've always been done, or because we lack the imagination to do things differently, or because we're not quite sure why we're studying these texts to begin with. This occurs in traditionalist environments and liberal ones, in formal settings and informal ones. We cover ground (biblical parashiot, chapters of Mishnah, folios of Talmud) in sequential fashion rather than carefully identifying our learning goals and creating the appropriate opportunities to help students meet those goals. We confuse knowledge of plot or peshat, the plain sense of the text, with substantive progress in the subject. We celebrate whimsical personal connections to the text, rather than the development of students' knowledge and ability to engage in meaningful textual interpretation. We prize the delivery of new insights by the teacher over the shared, disciplined investigation of the topic, and our assessments focus on the (momentary) retention of those insights. We get derailed by ideological disputes, mistaking them for pedagogical ones. And most of all, we tolerate a culture of idiosyncrasy, a pedagogic culture in which whatever lesson we come up with is good enough, so long as the students are at least minimally engaged.

Consider the following two anecdotes. ${ }^{10}$ The first one is about "Rabbi Kaufman," a senior rebbe in an Orthodox day school. After teaching his class the interpretation of the S'fas Emes (Yehudah Aryeh Leib of Ger, nineteenth-century Poland) of a passage in Leviticus, he noted that

10 The following paragraphs draw on Jon A. Levisohn, "A Plea for Purposes," Jewish Educational Leadership 4:1 (2005). 
he chose this particular interpretation of this particular verse at least in part because he happened to encounter the S'fas Emes the previous night, while preparing, and thought it might be interesting. In other words, his choice of the S'fas Emes emerged from a kind of browsing, an unfocused exploration with no clear conception of or stance toward the purposes of studying Jewish texts in general or this text specifically. For Rabbi Kaufman, preparing to teach means preparing to tell, preparing to transmit information that the teacher has discovered. As he candidly admitted about his own pedagogic choice, "I knew I wanted to tell them the new interpretation." Ironically, Rabbi Kaufman apparently lived his entire life without knowing this information-but suddenly, literally overnight, the interpretation of the S'fas Emes had become so important that the primary goal of the lesson was that the information should now reside, at least temporarily, in the students' heads.

In a second anecdote, from a very different point on the ideological spectrum, consider the case of "Carol," an experienced Reform supplementary school teacher, who encountered a source-critical analysis of the interwoven strands of the Korach narrative (Numbers chapters 16-18). She found the study session intriguing, stimulating, even compellingyet opined that she would never teach this material to the pre-teens in her classes. Is this a principled pedagogic position? Hardly. Carol does not, herself, believe in the Sinaitic origin of the text. Her students' parents do not, their rabbi does not, and it is almost certain that the students themselves will not as they grow into adolescence. Why, then, does she reject the teaching of human authorship-or more precisely, the exploration of the text through a critical lens - to her students? What purpose does the temporary preservation of a relic of traditionalism serve? What does Carol think about why she is teaching Torah in the first place?

The point of these anecdotes is that these teachers of Jewish texts lack a sense that curricular choices ought to be responsible to some larger framework of purposes. In Rabbi Kaufman's case, there seems to be nothing other than the instinctive inclusion of something that feels right. In Carol's case, there is nothing other than an instinctive exclusion of something that feels wrong. To these two anecdotes we might add the familiar phenomenon of novice teachers of Jewish texts casting about for curricular materials, via online networks or well-intentioned websites, to help them teach a particular topic or chapter that they find themselves assigned to teach. We should be sympathetic to these teach- 
ers, who find themselves adrift with little guidance, but the assembly of a random assortment of worksheets and activities cannot be the answer. This phenomenon, too, testifies to the state of the field. In all these cases, idiosyncrasy triumphs.

Some might argue that the appropriate response to idiosyncrasy is central planning, a coordinated effort to create a consensual curriculum. And indeed, some efforts to develop shared standards and to develop coherent curricula have shown promise. But to actually replace idiosyncrasy with uniformity is both highly improbable and almost certainly unwise. What is needed, alongside the development of proposed standards and thoughtful materials, is the development of the capacities of educators to use materials critically and well. And beyond this, what is needed is a culture of curiosity in this field, a way of talking and thinking about the teaching of classical Jewish texts that makes the familiar strange, that is not afraid to ask challenging questions or to experiment, that finds the work of teaching intellectually engaging and thought-provoking.

If teachers of classical Jewish texts were more consistently curious about their craft, and if they shared their curiosity with their colleagues in environments that supported that type of exploration, we might bootstrap our way out of our epidemic of idiosyncrasy. Curiosity, of course, is not the kind of thing that one can command. It may, however, be the kind of thing that one can spark. 